\title{
METHODS FOR MEASURING PULMONARY DYSFUNCTION IN CHILDREN
}

\author{
L. B. STRANG, M.D., M.R.C.P. \\ Postgraduate Medical School, London, W.12
}

ThE treatment of children with respiratory disease is at present handicapped by scanty knowledge of the functional disorders of the lungs which develop in these conditions. The extent and seriousness of respiratory illness as a cause of death in childhood can be appreciated from the figures in Table I which are derived from the Registrar General's report for 1959.

TABLE I

Registrar General, 1959 (England and Wales)

\begin{tabular}{c|c|c|c}
\hline $\begin{array}{c}\text { Age } \\
\text { (years) }\end{array}$ & $\begin{array}{c}\text { Total } \\
\text { Deaths }\end{array}$ & $\begin{array}{c}\text { Deaths } \\
\text { due to } \\
\text { Respiratory } \\
\text { Disease }\end{array}$ & $\begin{array}{c}\text { Respiratory } \\
\text { Deaths, } \\
\% \text { Total }\end{array}$ \\
\hline 0-1 & 16,629 & 4,733 & 28.4 \\
$1-4$ & 2,361 & 578 & 24.4 \\
$5-9$ & 1,351 & 164 & 12.1 \\
\hline Totals & 20,341 & 5,475 & 27.0 \\
\hline
\end{tabular}

These deaths are due mainly to pneumonia and to atelectasis and allied conditions in the newborn. In both cases death is due to respiratory insufficiency and it is reasonable to suppose that an improved understanding of this dysfunction could lead to the saving of many lives.

In addition to these deaths there is also a considerable morbidity connected with respiratory disease in childhood. This comes from the acute diseases which recover and from chronic illnesses such as asthma and bronchiectasis. It may also be that these conditions lead to chronic respiratory disease later in life. Thus the man who in middle age begins to suffer from breathlessness due to bronchitis or emphysema may be suffering the effects of a disease which started in childhood. This is not true of all chronic respiratory disease in adults but it may be true of a significant proportion of it.

\section{Difficulties of Measure ment in Childhood}

The main reason why respiratory function has not been studied very much in children is that it can be very difficult to make these measurements. Nevertheless it has already proved possible to make many significant observations in this field. In young infants a number of useful measurements have been made using the body plethysmograph invented by Cross, and in children of 6 years and over simple modifications of the kind of test used in adults have been used. In the age group between infancy and 6 years-important years in this connection-hardly any measurements have been made and research is urgently required in this field. Today I would like to talk about some of the tests (with which I have had experience) which are possible in children over 6 years and in infants. This is not intended to be a comprehensive review of the whole subject but rather a survey of some of the approaches available.

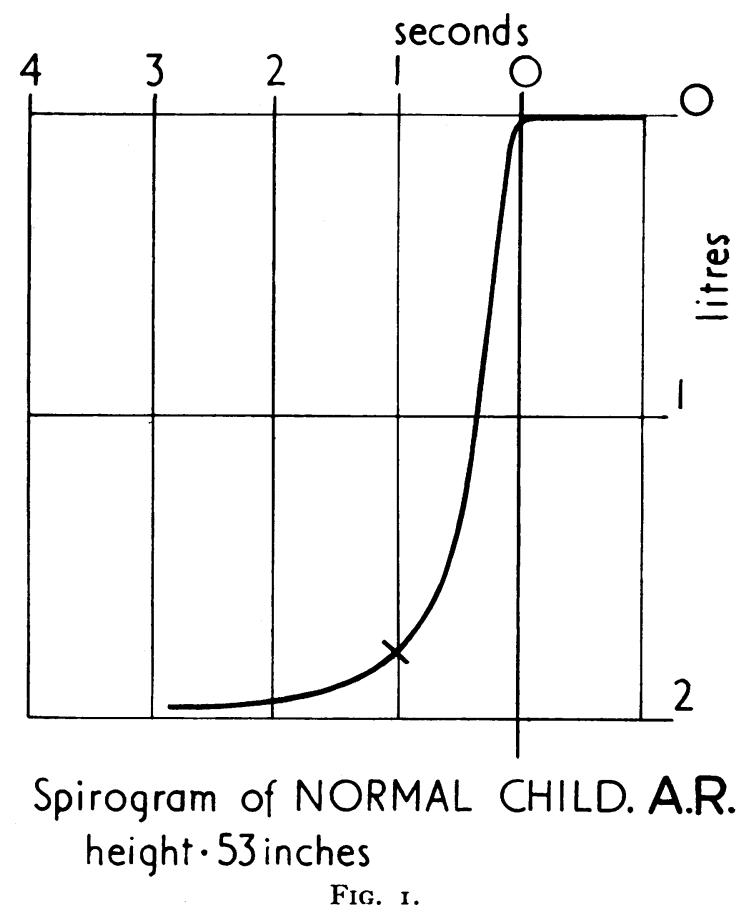




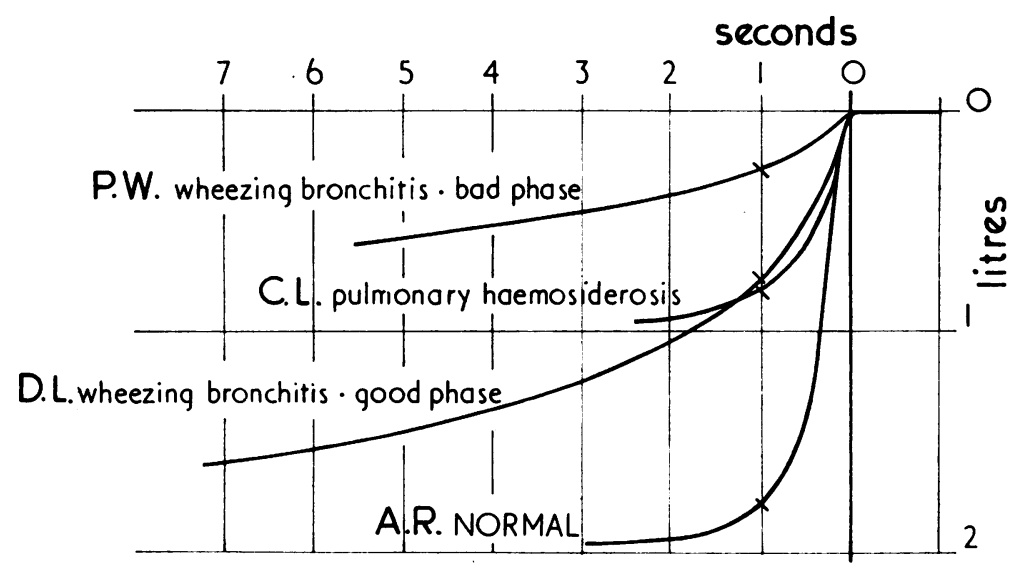

Comparison of SPIROGRAMS from 4 children

of the same height .53 ins

FIG. 2.

\section{Measurements in Children of 6 Years and Over}

Ventilatory capacity. Measurement of the ventilatory capacity can be carried out by the analysis of a single forced expiration recorded on a time base. In practice the child takes in as large a breath as possible and breathes out as fast and as far as possible into a spirometer with a light aluminium bell which records on a drum moving at a fixed rate. The volume of gas expelled in the first second is the Forced Expiratory Volume in one second $\left(\mathrm{FEV}_{1.0}\right)$. This is a measure of the individual's capacity for ventilation, and is comparable with the maximum breathing capacity which measures the volume which can be expired over a longer period (one minute).

Figure $I$ is a spirogram from a normal child. The vertical distance between the start of the trace and the mark at one second represents the FEV $_{1 \cdot 0}$. The total height of the tracing represents the Forced Vital Capacity (FVC). The ratio of $\mathrm{FEV}_{1.0}$ to $\mathrm{FVC}$ is normally 0.8 (this is usually expressed as ' FEV \%', 80\%).

Figure 2 compares the tracings of a normal child and of three others with chest disease. In the ill children the $\mathrm{FEV}_{1.0}$ is reduced-sometimes to very low levels. In the children with wheezing bronchitis (asthma) the FEV \% is also reduced, due to an obstruction to expired air flow which limits the rate of expiration more than its total volume. The child (C.L.) with pulmonary hæmosiderosis has a fibrosis of the lungs which limits the total excursion of lung movement but not the rate of expiration so that in this case the FEV \% is normal.

This simple method of measuring ventilatory capacity is very useful in assessing the course of asthma and bronchiectasis. In asthma one frequently finds evidence of bronchial obstruction when there are no symptoms - the illness being much less intermittent than would appear from the symptoms themselves. In bronchiectasis the most interesting finding is that there is often evidence of ventilatory impairment due to diffuse bronchial obstruction in cases which would appear to be localized from the radiograph. Indeed, persistent ventilatory impairment is commoner than might be expected and it is likely that this could lead to a life-long disability.

\section{Diffusing Capacity}

Pulmonary diffusing capacity in children can also be measured using carbon monoxide in low concentrations. Both multi-breath and singlebreath procedures have been used. The simplest method is for the child to breathe from a bag containing $0.1 \%$ carbon monoxide and to collect the expired gas in another bag. However, abnormalities of diffusing capacity are rare in children. They are likely to been countered in conditions such as the Hamman-Rich syndrome and other diffuse interstitial diseases. Fig. 3 shows results in two children with diffuse disease of the lungs. The lines indicate the mean and $95 \%$ limits of normal in children for height, and it will be seen that the child with the fibrocystic disease of the pancreas was within them but that the child with pulmonary hæmosiderosis was seriously abnormal.

\section{Measurements in Infants}

The technique in infants of which $I$ have 
experience uses a respiratory mass spectrometer (developed by Dr. K. T. Fowler at Hammersmith Hospital under the auspices of the Medical

- idiopathic pulmonary haemosiderosis

$\square$ fibrocystic disease of pancreas

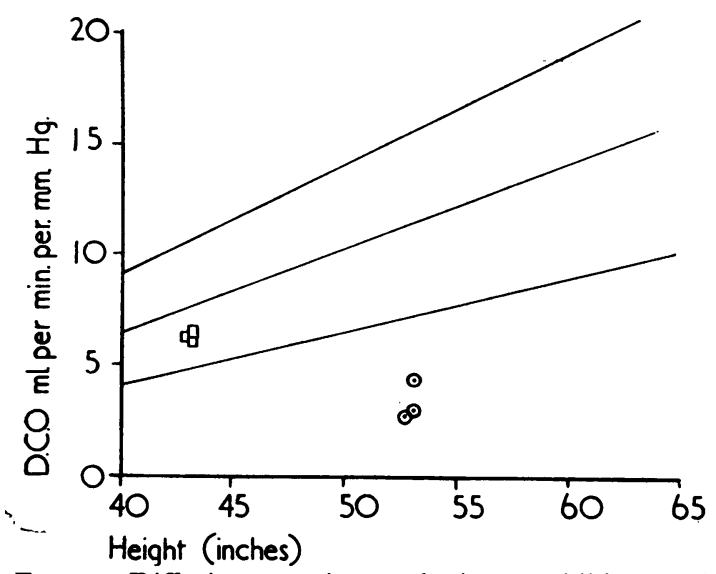

FIt: 3.-Diffusing capacity results in two children with interstitial lung disease. The lines indicate the normal mean for height in children \pm 2 standard deviations.
Research Council). The infant's ventilation is measured using a Cross plethysmograph and at the same time a fine sampling tube is placed just within the infant's nostril. The mass spectrometer provides a rapid instantaneous analysis of oxygen, carbon dioxide and nitrogen tensions in the expired gas, and volume change from the plethysmograph is recorded on the same chart.

Various modifications of this technique permit measurement of alveolar gas tensions and of variations in ventilation, in ventilation-perfusion ratio, in dead space volume and in alveolar volume in the infant. Research at present under way is investigating the normal development of the aircontaining lung and the changes which occur in babies with respiratory distress. Evidence is accumulating that these infants suffer from a marked reduction of alveolar ventilation and from a disturbance of pulmonary blood flow which is probably a consequence of the ventilatory failure.

\section{Conclusion}

A small amount of headway has been made in understanding the respiratory dysfunction which accompanies lung disease in children. I hope that I have shown you some of the ways in which these problems can be tackled.

\section{Dr. P. Forgacs, M.D., M.R.C.P. \\ (Consultant in Diseases of the Chest, S.E. Metropolitan Regional Hospital Board)}

1 listened with much interest to Dr. Strang's remarks on the technical difficulties of carrying out respiratory measurements on young children. On the few occasions when we have been asked to measure the $\mathrm{CO}_{2}$ tension in children with suspected ventilatory failure, the choice between an arterial puncture and the collection of rebreathed gas with a bag and a face mask was always difficult. Children dislike both these procedures. The difficulty does not arise in children who are already being ventilated by a positive pressure machine through a tracheostome, because the pump can then be replaced by a rubber bag squeezed by hand and rebreathed alveolar gas can be collected. Sampling of end-expiratory gas cannot be relied on, unless continuous analysis shows that a plateau for $\mathrm{CO}_{2}$ tension exists.

In situations, particularly in very young children, where both arterial sampling and rebreathing is difficult for technical reasons, I would suggest tentatively a method we have often applied to the monitoring of $\mathrm{PCO}_{2}$ in artificially ventilated adults. This consists of injecting 50 or $60 \mathrm{ml}$. of air under the skin in the dorsal aspect of the forearm, and allowing it to equilibrate with the $\mathrm{CO}_{2}$ tension of the surrounding tissues. Equilibration is com- plete at 80 minutes, after which gas samples can be withdrawn for analysis. Such a subcutaneous gas depot can be replenished and maintained, if necessary, for several days.

This may be the proper occasion to report an observation which throws some light on the controversy whether the administration of oxygen to infants by gastric catheter or other extrapulmonary routes is likely to be successful or not. In 1959 we carried out an experiment on a patient with severe $\mathrm{CO}_{2}$ retention $\left(\mathrm{PCO}_{2}: 86 \mathrm{~mm}\right.$. $\left.\mathrm{Hg}\right)$ to see how much $\mathrm{CO}_{2}$ can be washed out by peritoneal dialysis. Six litres of air were passed through the peritoneal cavity in 25 minutes $(240 \mathrm{ml}$./min.). The gas collected after passage through the peritoneal cavity contained $1.9 \%$ carbon dioxide. The rate of $\mathrm{CO}_{2}$ washout was therefore $4.5 \mathrm{ml}$. $/ \mathrm{min}$. Assuming a rate of $\mathrm{CO}_{2}$ production of $25^{\circ}$ $\mathrm{ml} . / \mathrm{min}$., less than $2 \%$ of this amount has been removed. This trifling contribution to $\mathrm{CO}_{2}$ excretion is obviously not worth the trouble. The limiting factor is the relatively small blood flow past the diffusing surface. Conditions for the transfer of oxygen in similar circumstances are likely to be even less favourable. 